\title{
Treatment of relapse of small cell lung cancer in selected patients with the initial combination chemotherapy carboplatin, etoposide, and epirubicin
}

\author{
Ph Collard, P Weynants, Ch Francis, D O Rodenstein
}

\begin{abstract}
Background Relapse of small cell lung cancer is not usually treated with further chemotherapy as results are considered to be disappointing.

Methods and results Six patients with relapse of small cell lung cancer after a complete initial response and remission of more than one year responded to repeat treatment with the initial chemotherapy comprising carboplatin, etoposide, and epirubicin. The second remission ranged from six months to more than 15 months.

Conclusion In patients with a relapse of small cell lung cancer after a complete initial response and prolonged remission retreatment with the initial combination chemotherapy cannot be dismissed and requires further study.
\end{abstract}

Small cell lung cancer has an aggressive course and is usually widespread at presentation. Surgery has been advocated in truly limited disease, but this is rare. ${ }^{1}$ The best therapeutic approach for the time being is chemotherapy. Several combination regimens administered over three to six months have improved median survival and there is at present no clear advantage for any particular regimen. ${ }^{2}$ Unfortunately, the disease usually relapses a few months after discontinuation of chemotherapy and the benefit of further treatment at this stage is less clear.

We report six patients with disease relapse who showed a good response to a repeat course of chemotherapy with the initial drug regimen of carboplatin, etoposide, and epirubicin. ${ }^{3}$

\section{Case reports}

From January 1987 to December 1990 small cell lung cancer was diagnosed in 78 patients, 36 with limited disease and 42 with extensive disease. All were treated with intravenous carboplatin $330 \mathrm{mg} / \mathrm{m}^{2}$ and epirubicin 60 $\mathrm{mg} / \mathrm{m}^{2}$ on day 1 and intravenous etoposide $120 \mathrm{mg} / \mathrm{m}^{2}$ on days 1,3 , and 5 ; courses were separated by three week intervals. The effect of the carboplatin-etoposide-epirubicin regimen was not assessed in 15 patients as they received less than two courses of chemotherapy. Of the remaining 63 patients, six were non-responders, 33 partial responders, and 24 complete responders ( 18 of whom had limited disease at initial staging); in most of the complete responders chemotherapy was followed by radiotherapy to the primary tumour mass (60 Gy) and the mediastinum (50 Gy), and they also received prophylactic cranial irradiation ( $30 \mathrm{~Gy}$ ). Of the 24 complete responders, 12 relapsed early (less than 12 months after stopping treatment) and seven had a late relapse (all had had limited disease initially); five patients have not yet relapsed. The patients with a late relapse were treated with further courses of carboplatinetoposide-epirubicin and are described in this paper.

The clinical characteristics and the response to treatment of six of the patients are summarised in the table. Clinical tolerance to chemotherapy was excellent in all cases and no febrile episodes occurred; patient 2 required an occasional blood transfusion during chemotherapy. The six patients experienced considerable improvement in symptoms and gained weight after repeat treatment with carboplatin-etoposide-epirubicin; patients 1 and 3 returned to sedentary work for several months while in their second remission.

\begin{tabular}{|c|c|c|c|c|c|c|}
\hline & \multicolumn{6}{|l|}{ Patient No: } \\
\hline & 1 & 2 & 3 & 4 & 5 & 6 \\
\hline $\begin{array}{l}\text { Sex, age }(y) \\
\text { Initial extension } \\
\text { Initial treatment } \\
\text { First response } \\
\text { Remission (months) } \\
\text { Relapse site } \\
\text { Relapse treatment } \\
\text { Second response } \\
\text { Remission (months) } \\
\text { Final relapse site } \\
\text { Survival (months) }\end{array}$ & $\begin{array}{l}\text { M, } 57 \\
\text { Limited } \\
4 \mathrm{Cx}, \mathrm{LI}, \mathrm{CI} \\
\text { Complete } \\
19 \\
\text { Local and brain } \\
6 \mathrm{Cx} \\
\text { Complete } \\
10 \\
\text { Brain } \\
32\end{array}$ & $\begin{array}{l}\text { F, } 59 \\
\text { Limited } \\
6 \mathrm{Cx}, \mathrm{CI} \\
\text { Complete } \\
17 \\
\text { Local } \\
6 \mathrm{Cx} \\
\text { Complete } \\
11 \\
\text { Brain } \\
28\end{array}$ & $\begin{array}{l}\text { M, } 62 \\
\text { Limited } \\
6 \text { Cx, LI, CI } \\
\text { Complete } \\
22 \\
\text { Local } \\
4 \text { Cx } \\
\text { Partial } \\
6 \\
\text { Brain } \\
28\end{array}$ & $\begin{array}{l}\text { F, } 62 \\
\text { Limited } \\
4 \mathrm{Cx}, \mathrm{LI}, \mathrm{CI} \\
\text { Complete } \\
31 \\
\text { Local } \\
4 \mathrm{Cx} \\
\text { Partial } \\
12 \\
\text { Local and liver } \\
51\end{array}$ & $\begin{array}{l}\text { M, } 60 \\
\text { Limited } \\
6 \mathrm{Cx}, \mathrm{LI}, \mathrm{CI} \\
\text { Complete } \\
21 \\
\text { Local } \\
4 \mathrm{Cx} \\
\text { Partial }\end{array}$ & $\begin{array}{l}\text { F, } 71 \\
\text { Limited } \\
6 \mathrm{Cx}, \mathrm{CI} \\
\text { Complete } \\
29 \\
\text { Local and liver } \\
4 \mathrm{Cx} \\
\text { Partial }\end{array}$ \\
\hline
\end{tabular}

$\mathrm{Cx}$-polychemotherapy course with carboplatin, etoposide, and epirubicin; LI-local irradiation; CI—cranial irradiation. 
Figure 1 Patient 1: Thoracic computed tomogram at the level of the heart at the initial presentation, showing a right lower lobe mass extending to the mediastinum (left) and complete response after three carboplatinetoposide-epirubicin polychemotherapy induction courses (right).

Figure 2 Patient 1: Thoracic computed tomogram at the same level at relapse, showing recurrence of the right lower lobe tumour (left) and resolution after three carboplatin-etoposideepirubicin

polychemotherapy reinduction courses (right).

Figure 3 Patient 1: Cerebral computed tomogram at relapse, showing the parietal metastasis (arrow, left) and its disappearance after three carboplatinetoposide-epirubicin polychemotherapy reinduction courses (right).
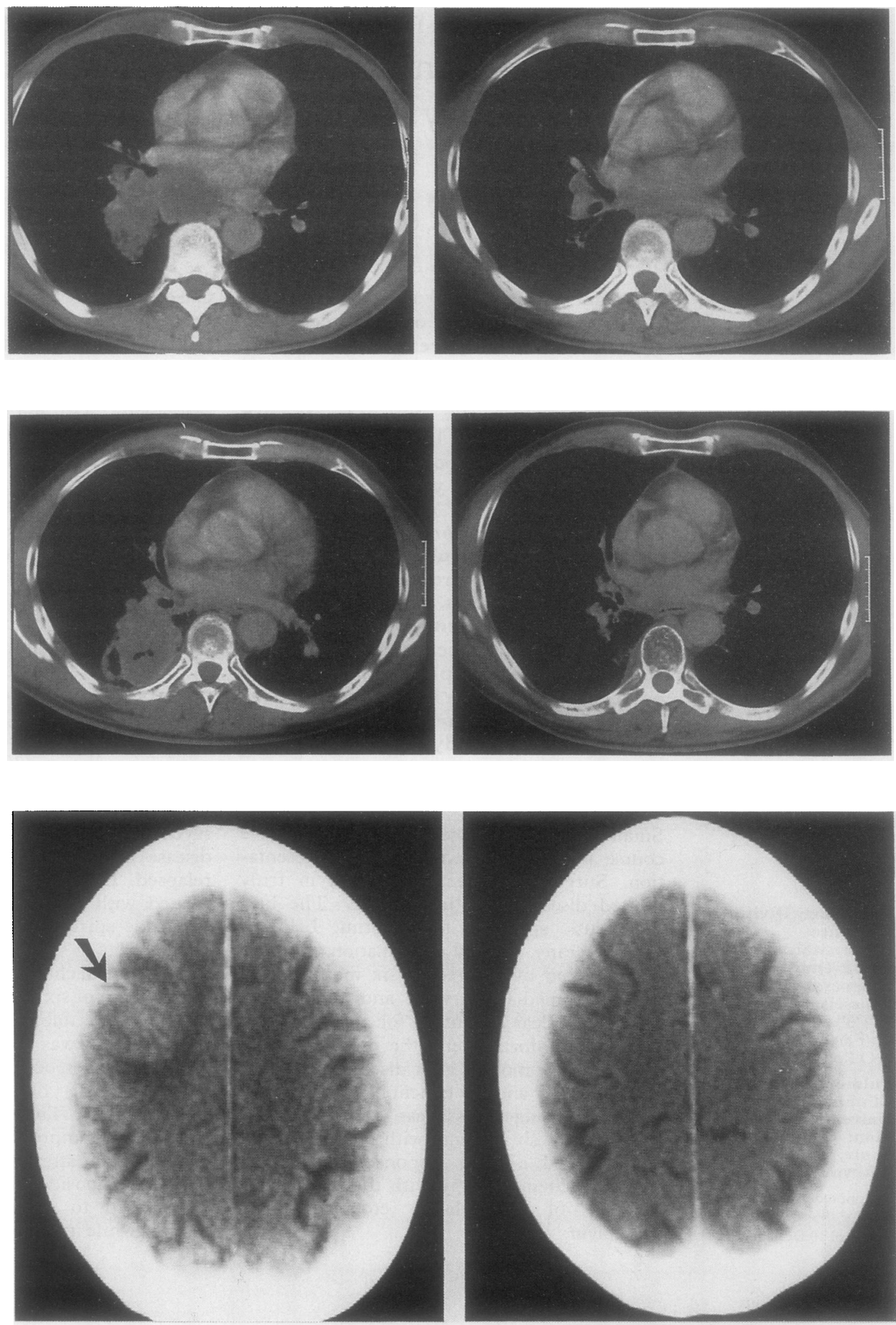

The seventh patient, with a late relapse of small cell lung cancer, developed left lung atelectasis from an occluded main bronchus 15 months after achieving a complete response from carboplatin-etoposide-epirubicin induction treatment. He was treated again with carboplatin-etoposide-epirubicin but died after a single course from an infected perineal haematoma (presumably facilitated by the chemotherapy induced pancytopenia). There was already an objective response to the repeat treatment, with evidence of aeration of the left lung; he survived for 23 months after diagnosis.

\section{Discussion}

A four to eight course induction chemotherapy regimen is regarded as standard initial treatment for small cell lung cancer. Most studies have shown that maintenance or late intensification treatment does not provide 
appreciable survival advantage and may in fact be deleterious in terms of quality of life. ${ }^{24-6}$ With modern induction treatment a complete response is achieved in a growing number of patients, who subsequently enjoy several months of good quality remission.

Treatment policy on relapse is controversial and many patients and physicians are reluctant to consider further chemotherapy. ${ }^{7} \mathrm{~A}$ recent editorial states that further chemotherapy after the induction phase is not useful and that survival is not improved. ${ }^{8}$ It is also widely believed that if further treatment is prescribed it should be based on drugs other than those used in the induction regimen.

When a patient has shown a complete response to induction treatment we have elected to use the same treatment for relapse. As these cases show, we have had encouraging results with minimal toxicity. So far we have observed a response to relapse treatment with carboplatin-etoposide-epirubicin in every patient meeting the conditions of a complete initial response and a prolonged first remission of at least 12 months after finishing induction treatment.

A further course of induction treatment has proved effective in other malignancies, such as breast cancer, ${ }^{10}$ ovarian cancer, ${ }^{11}$ multiple myeloma, ${ }^{12}$ and Hodgkin's disease. ${ }^{13}$ A few studies have indicated that further treatment with the initial chemotherapeutic regimen may be effective in patients with small cell lung cancer who relapse after a short induction course. ${ }^{14-16}$ The response to initial treatment, the length of remission, and performance status may have prognostic significance in this context. As in our cases, the complete response rate and duration of remission tend to be shorter after reinduction chemotherapy than after the initial treatment. The carboplatin-etoposide-epirubicin chemotherapy appeared to be active against disease at other sites, including cerebral metastases (table and figs 1-3), as has been found with initial treatment. ${ }^{3}$

In contrast to the results in these patients, the response rate with salvage treatment (whether carboplatin-etoposide-epirubicin; an alternative chemotherapy regimen consisting of cyclophosphamide, doxorubicin, vincristine, and methotrexate; or radiotherapy) has been very poor in our hands for patients with an initial partial response or short term remission after complete response to induction treatment with carboplatin-etoposideepirubicin.

Although a definite policy on relapse treatment will be arrived at only after large scale randomised trials, our preliminary experience suggests that using the same carboplatin- etoposide-epirubicin chemotherapy regimen for relapse in small cell lung cancer may be an effective (albeit palliative) treatment provided that the initial response was complete and the first remission was prolonged.

Although the response to chemotherapy at relapse is disappointing for most patients with small cell lung cancer, identifying patients likely to derive benefit from repeated chemotherapy is important, in terms both of survival and of quality of life. The subgroup we have defined represents about $10 \%$ of patients with small cell lung cancer. If our findings are confirmed in a larger number of patients, with similar characteristics, the current policy of no further treatment after relapse will need to be revised so that patients will not be denied a potentially useful and well tolerated retreatment.

We thank Dr Y Humblet for his useful comments on the manuscript.

1 Crompton G. Small cell lung cancer [editorial]. BMJ 1990; 300:209-10.

2 Feld R, Ginsber RJ, Payne DG. Treatment of small cell lung cancer. In: Roth JA, Ruckdeschel JC, Weisenburger TH, eds. Thoracic oncology. Philadelphia: Saunders, 1989: 229-62.

3 Humblet Y, Weynants P, Bosly A, et al. Carboplatin in association with etoposide and either Adriamycin or epirubicin for untreated small cell lung cancer: a dose escalation study of carboplatin. Med Oncol Tumor escalation study of carbop
Pharmacother 1989;6:207-12.

4 Medical Research Council Lung Cancer Working Party. Controlled trial of twelve versus six courses of chemotherapy in the treatment of small cell lung cancer. $\mathrm{Br} J$ Cancer 1989;59:584-90.

5 Leonard RCF. Small cell lung cancer [editorial]. Br J Cancer 1989;59:487-90.

6 Byrne MJ, van Hazel G, Trotter J, et al. Maintenance chemotherapy in limited small cell lung cancer: a randomised controlled clinical trial. Br J Cancer 1989; 60:413-8.

7 Spiro SG, Souhami RL, Geddes DM, et al. Duration of chemotherapy in small cell lung cancer: a Cancer Research Campaign trial. Br J Cancer 1989;59:578-83.

8 Spiro SG, Souhami RL. Duration of chemotherapy in small cell lung cancer [editorial]. Thorax 1990;45:1-2.

9 Wendt AG, Jones SE, Salmon SE. Salvage treatment of patient relapsing after breast cancer adjuvant chemotherapy. Cancer Treat Rep 1980;64:269-73.

10 Buzdar AU, Legha SS, Hortobagyi GN, et al. Management of breast cancer patients failing adjuvant chemotherapy with Adriamycin-containing regimens. Cancer 1981;47: with Adriam.

11 Seltzer V, Vogl S, Kaplan B. Recurrent ovarian carcinoma: retreatment utilizing combination chemotherapy including cisdiamminedichloroplatinum in patients previously responding to this agent. Gynecol Oncol 1985;21:167-76.

12 Alexanian R, Gehan E, Haut A, et al. Unmaintained remission in multiple myeloma. Blood 1978;51:1005-11.

13 Fisher RI, DeVita VT, Hubbard SP, et al. Prolonged disease-free survival in Hodgkin's disease with MOPP reinduction after first relapse. Ann Intern Med 1979; 90:761-3.

14 Batist G, Ihde DC, Zabell A, et al. Small cell carcinoma of lung: reinduction therapy after late relapse. Ann Intern Med 1983;98:472-4.

15 Postmus PE, Berendsen HH, Van Zandwijk N, et al. Retreatment with the induction regimen in small cell lung cancer relapsing after an initial response to short term chemotherapy. Eur J Cancer Clin Oncol 1987;23:1409-11.

16 Giaccone G, Ferrati P, Donadio M, et al. Reinduction chemotherapy in small cell lung cancer. Eur J Cancer Clin Oncol 1987;23:1697-9. 